\title{
A review of gambling disorder and substance use disorders
}

This article was published in the following Dove Press journal:

Substance Abuse and Rehabilitation

17 March 2016

Number of times this article has been viewed

\author{
Carla J Rash' \\ Jeremiah Weinstock ${ }^{2}$ \\ Ryan Van Patten ${ }^{2}$ \\ 'Calhoun Cardiology Center - \\ Behavioral Health, UConn Health, \\ Farmington, CT, USA; ${ }^{2}$ Department \\ of Psychology, Saint Louis University, \\ St Louis, MO, USA
}

\begin{abstract}
In the fifth edition of the Diagnostic and Statistical Manual of Mental Disorders (DSM-5), gambling disorder was recategorized from the "Impulse Control Disorder" section to the newly expanded "Substance-related and Addictive Disorders" section. With this move, gambling disorder has become the first recognized nonsubstance behavioral addiction, implying many shared features between gambling disorder and substance use disorders. This review examines these similarities, as well as differences, between gambling and substance-related disorders. Diagnostic criteria, comorbidity, genetic and physiological underpinnings, and treatment approaches are discussed.

Keywords: pathological gambling, problem gambling, behavioral addiction, transdiagnostic factors, addiction syndrome
\end{abstract}

\section{Introduction}

Gambling disorder (GD) is a persistent maladaptive pattern of gambling resulting in clinically significant impairment or distress. ${ }^{1}$ In order to meet the criteria, individuals must exhibit four or more of the nine symptoms within a 12 -month period. GD can present as either episodic or persistent and is rated as mild, moderate, or severe according to the number of symptoms endorsed. In the fifth edition of the Diagnostic and Statistical Manual of Mental Disorders (DSM-5), ${ }^{1}$ pathological gambling was renamed GD and recategorized from an impulse control disorder to an addictionrelated disorder, highlighting longstanding conceptualizations of GD as an addiction. The links between GD and alcohol and drug use disorders (AUD/DUD) are numerous and include analogous diagnostic criteria, high comorbidity rates, shared genetic underpinnings, similar neurobiological effects, and common treatment approaches. For the purposes of this review, AUD refers to either alcohol abuse or dependence and DUD refers to any illicit or nonmedical (nontobacco, nonalcohol) drug abuse or dependence disorder unless otherwise noted. In light of GD's reclassification as the first non-substance behavioral addiction, this paper will provide an overview of the potential links between GD and AUD/DUD from etiology to treatment approaches with emphasis on areas impacted by the DSM-5 classification.

\section{Diagnostic criteria}

Significant construct overlap is present across DSM-5 GD and AUD/DUD, given that the original DSM-III gambling criteria were modeled largely on the substance dependence criteria of the time. ${ }^{2}$ However, important differences do exist across the two diagnostic sets, and, consequently, the DSM-5 substance use disorder (SUD) Work
Calhoun Cardiology Center - Behavioral Health, UConn Health, 263 Farmington Avenue (MC 3944), Farmington, CT 06030,USA

Email carlarash@gmail.com 
Group recommended adoption of the DSM-IV GD criteria with modifications rather than adapting the SUD criteria for GD. ${ }^{3}$ In Table 1, we list the criteria for GD and AUD, highlighting overlapping or similar content items. Items with the strongest content overlap include tolerance, withdrawal, loss of control, and negative consequences. With respect to the latter construct, GD has one item related to negative impact on social, educational, or work domains; for AUD, four items describe negative impacts to more varied life domains (eg, psychological health, physical health). The AUD/DUD criteria set, including these negative consequences items, is likely to be reviewed for redundancy and possible streamlining in future DSM editions, ${ }^{3}$ thereby facilitating greater diagnostic consistency between addictive disorders. Conversely, GD's negative consequences item might be expanded to include other relevant domains such as psychological health, which is often negatively impacted in those with the disorder. ${ }^{4,5}$ Specifically, both rates of comorbidity ${ }^{6}$ and risk of suicide ideation and attempts ${ }^{7,8}$ have been shown to be elevated in individuals with GD.

A second relevant shared diagnostic feature is fixation upon the addictive behavior. In GD, this construct is referred to as preoccupation with gambling, and it concerns reliving past gambling experiences, planning future gambling experiences, and strategizing ways to fund gambling. For AUD, a comparable item pertaining to spending a great deal of time obtaining, using, or recovering from alcohol use corresponds with some of the planning features evident in the GD item. However, the AUD item does not fully address the cognitive component of preoccupation represented in GD. The craving item from the alcohol criteria, new to DSM-5, may capture a portion of this cognitive construct. A craving item was not added to the GD criteria, which do not explicitly address cravings. Although evidence suggests that cravings are common among individuals with $\mathrm{GD}^{9,10}$ and that they are related to gambling behavior, ${ }^{11,12}$ the question of whether cravings are central to the diagnosis of GD, as in SUD, remains unanswered. The remaining items, four from GD and one from AUD, do not have a corresponding criterion in each disorder set and highlight unique aspects of each disorder (eg, chasing losses). Questions remain about whether shaping the GD criteria to more closely model the SUD criteria set is advantageous for diagnosis of GD and for diagnostic consistency within the section.

Table I Comparison of DSM-5 gambling disorder and alcohol use disorder criteria

\begin{tabular}{|c|c|c|}
\hline Construct & Gambling disorder & Alcohol use disorder \\
\hline Tolerance & $\begin{array}{l}\text { Gambles with more money in order to achieve the } \\
\text { desired excitement }\end{array}$ & $\begin{array}{l}\text { Using increasing amounts of alcohol to achieve intoxication } \\
\text { or desired effect; or diminished effect when using the same } \\
\text { amount of alcohol }\end{array}$ \\
\hline Loss of control & $\begin{array}{l}\text { Unsuccessful attempts to control, limit, or stop } \\
\text { gambling }\end{array}$ & $\begin{array}{l}\text { Desire or unsuccessful attempts to cut down or control use } \\
\text { Using larger amounts or over a longer period than intended }\end{array}$ \\
\hline Withdrawal & $\begin{array}{l}\text { Restlessness or irritability when trying to control } \\
\text { gambling }\end{array}$ & $\begin{array}{l}\text { Alcohol withdrawal symptoms or use of alcohol (or related } \\
\text { substances) to relieve or avoid withdrawal symptoms }\end{array}$ \\
\hline Negative consequences & $\begin{array}{l}\text { Risked or lost a significant relationship, educational, } \\
\text { or work-related opportunity because of gambling }\end{array}$ & $\begin{array}{l}\text { Continued use despite social or interpersonal problems related } \\
\text { to alcohol use } \\
\text { Alcohol use leading to neglect of major role obligations at } \\
\text { work, school, or home } \\
\text { Gave up important social, occupational, or recreational } \\
\text { activities because of alcohol use } \\
\text { Continued use despite physical or psychological problems that } \\
\text { are likely to have been caused or worsened by alcohol }\end{array}$ \\
\hline Fixation & $\begin{array}{l}\text { Preoccupation with gambling-related thoughts such } \\
\text { as reliving past gambling experiences, planning future } \\
\text { experiences, or strategizing ways to fund gambling } \\
\text { behavior }\end{array}$ & $\begin{array}{l}\text { Excessive time spent obtaining, using, or recovering from } \\
\text { alcohol } \\
\text { Cravings, strong desire, or urges to use alcohol }\end{array}$ \\
\hline Negative affect & Frequently gambles in response to negative affect & \\
\hline Chasing losses & $\begin{array}{l}\text { Often follows gambling losses by returning another } \\
\text { day to recoup money }\end{array}$ & \\
\hline Lying & Lies about gambling or gambling-related consequences & \\
\hline Bailouts & $\begin{array}{l}\text { Depends on others for money to alleviate desperate } \\
\text { financial situations caused by gambling }\end{array}$ & \\
\hline Hazardous situations & & Recurrent use in physically hazardous situations \\
\hline
\end{tabular}

Abbreviation: DSM-5, Diagnostic and Statistical Manual for Mental Disorders, fifth edition. 


\section{Prevalence}

AUD exhibits high prevalence rates relative to many other psychiatric conditions. For example, lifetime and past-year prevalence rates of AUD were $30.3 \%$ and $8.5 \%$, respectively, in the National Epidemiologic Survey on Alcohol and Related Conditions (NESARC). ${ }^{13}$ These rates are substantially higher than prevalence rates of any nontobacco DUD (lifetime: 10.3\%, past-year: $2.0 \%$ ) and major depressive disorder (lifetime: $13.2 \%$, past-year: $5.3 \%) \cdot{ }^{13}$ Results from nationally representative samples estimate a substantially lower prevalence for GD with $\sim 1 \%-2 \%$ meeting lifetime criteria and half of that meeting past-year criteria. ${ }^{14-17}$ Young age, male sex, low socioeconomic status, and unpaired marital status (ie, never married, divorced, separated, widowed) are common demographics shared by individuals with GD and AUD/DUD. ${ }^{13,15-17}$

\section{Diagnostic threshold}

In the DSM-5, the diagnostic threshold for GD was lowered from five of ten criteria to the current threshold of four of nine criteria. ${ }^{1}$ The changes done by the DSM-5 SUD Work Group to the GD criteria were designed to minimize impact on prevalence rates while improving diagnostic accuracy. ${ }^{18}$ Nonetheless, modest increases in GD prevalence rates are likely as $D S M-5$ criteria are adopted. For example, in a sample of randomly selected US household residents $(\mathrm{N}=2,417)$, prevalence rates of GD increased from $0.1 \%$ to $0.2 \%$ using the $D S M-5$ criteria. ${ }^{19}$ Samples from clinical settings that serve high-risk gamblers will also be affected. Prevalence of GD increased from $81.2 \%$ under $D S M-I V$ to $90.3 \%$ using $D S M-5$ criteria among West Virginian gamblers $(\mathrm{N}=2,750)$ calling a state gambling help line. ${ }^{8}$

Despite a lower threshold, stark differences remain between SUD and GD in terms of diagnostic thresholds and recognition of milder forms of the disorder. ${ }^{8,20}$ For the DSM-5 SUD criteria, which combine DSM-IV substance abuse and dependence items in a single diagnostic set, only two or more of eleven symptoms are required for diagnosis. Severity is indicated with mild ( $2-3$ symptoms), moderate ( $4-5$ symptoms), and severe (six or more symptoms) specifiers, which is incongruent with GD severity specifiers: mild (4-5 symptoms), moderate (6-7 symptoms), and severe (8-9 symptoms).

If GD criteria were to be more directly modeled after SUD criteria with its lower threshold, the prevalence rate of GD would rise significantly, as an additional $2 \%$ of individuals endorse subclinical lifetime gambling problems..$^{14,15}$ Consideration of such a change, despite the potential impact on prevalence rates, may be warranted if individuals with subthreshold GD symptoms experience clinically significant levels of impairment or harm on par with mild AUD/SUD and if they benefit from identification and treatment. Several studies document substantial negative impacts associated with subclinical gambling, including increased risk of comorbidity, ${ }^{6,21}$ financial problems and gambling-related debt, ${ }^{8}$ and suicide ideation and attempts. ${ }^{7}$ Given these significant consequences, as well as the high rates of comorbidity between AUD/DUD and GD (discussed in the following section), consistency among these diagnostic sets may assist clinicians by applying a single set of criteria and severity ratings across disorders.

\section{Comorbidity GD and psychiatric disorders}

Comorbidity with other psychiatric disorders, including other addictions, is common in both AUD/DUD and GD. As many as $96 \%$ of individuals with lifetime GD also meet criteria for at least one other lifetime psychiatric disorder. ${ }^{6,15}$ Lifetime rates of many psychiatric disorders are elevated among those with GD, ${ }^{16}$ with mood $(49 \%-56 \%)^{15,16}$ and anxiety $(41 \%-60 \%)^{15,16}$ disorders and AUD $(73 \%)^{16}$ and DUD $(38 \%)^{16}$ being particularly prevalent. ${ }^{15}$ Personality disorders are also more common among those with $\mathrm{GD}^{16}$ and the prevalence of multiple comorbid disorders is increased as well. Specifically, in a cross-sectional study, ${ }^{15}$ individuals with GD were 30 times more likely to have multiple (three or more) other lifetime psychiatric disorders compared to those without GD. Moreover, this retrospective study suggests that the majority of this comorbidity (74\%) precedes and may be a risk factor for the development of GD rather than GD serving as a risk factor for the development of other psychiatric disorders. However, longitudinal prospective studies, ${ }^{22,23}$ which are advantageous for establishing temporal sequence of disorder onset, suggest that past-year GD is associated with the subsequent development of new psychiatric conditions including mood, anxiety, and AUD. The risk of developing new disorders appears to be associated with the severity of gambling behavior, ${ }^{23}$ with diagnosed gamblers at greatest risk for onset of a new comorbid disorder compared to problem or recreational gamblers. Overall, the literature supports a bidirectional relationship with respect to comorbidity such that psychiatric disorders can serve as risk factors in the development of, can serve as maintenance factors in GD, and can arise as consequences of GD..$^{15,22,24}$

\section{GD and AUD/DUD}

GD's association with other addictive disorders is well established. Population-based meta-analytic estimates 
suggest high rates of lifetime AUD and DUD comorbidity among lifetime problem and pathological gamblers, with $28 \%$ of gamblers reporting an AUD and 17\% reporting an illicit DUD. ${ }^{25}$ These prevalence rates are best understood by comparing the difference in rates of SUD/DUD diagnoses among those with and without GD. For example, in the Welte et $\mathrm{al}^{17}$ study, $25 \%$ of those with GD met criteria for current alcohol dependence, whereas only $1.4 \%$ of those without GD were alcohol dependent. Echoing the discussion of multicomorbidity noted earlier, the presence of dual addictive disorders, such as concurrent AUD and GD, is associated with increased risk of additional psychiatric disorders compared to the presence of GD without AUD. ${ }^{26}$

AUD and DUD are also more common among treatmentseeking gamblers than in the general population, with as many as $41 \%$ meeting criteria for lifetime AUD and $21 \%$ meeting criteria for nonalcohol SUDs including nicotine dependence. ${ }^{27}$ Comorbid DUD impacts gambling outcomes such that those with no lifetime history of DUD are 2.6 times more likely to achieve a 3-month period of gambling abstinence compared to those with lifetime DUD. ${ }^{28}$ Another study $^{29}$ suggests that even among those with lifetime AUD/ DUD, a majority (58\%) of those seeking gambling treatment are actively using alcohol or illicit substances in the year prior to admission for gambling treatment. Fortunately, at-risk alcohol use (more than 14 standard drinks/week or 4/day for males; more than 7 drinks/week or 3 drinks/day for females) does appear to decrease during gambling treatment, ${ }^{30}$ and these naturally occurring reductions in alcohol use might be enhanced with the incorporation of brief alcohol interventions into gambling treatments. Such treatments may reduce the possibility of progression to disordered levels of alcohol use, the presence of which is associated with gambling relapse. ${ }^{28}$ These concurrent changes in alcohol use and gambling suggest that these behaviors may influence each other over time.

Given the high prevalence rates and the impact of comorbid DUD and AUD on gambling outcomes, inclusion of AUD and DUD screening procedures in clinical practice is recommended for patients with GD. The converse, screening for problematic gambling among substance abuse treatment seekers, is also warranted. Approximately, $15 \%$ of AUD/DUD treatment seekers meet lifetime criteria for GD and 11\% meet current criteria for GD. ${ }^{31}$ Among opioid substitution patients, rates of GD may be even higher, ${ }^{31}$ and problem gambling is associated with poorer response to substance abuse treatment among these patients. ${ }^{32}$ Integration of gambling screening and referral processes into substance abuse treatment may improve not only the gambling problem, but also AUD/DUD treatment outcomes. In addition, many individuals with AUD/DUD are able to achieve sobriety from alcohol and drugs, but are unable to control their gambling, ${ }^{29}$ suggesting gambling-specific or integrated treatments may be necessary for treatment success of both disorders in substance abuse treatment settings.

\section{GD diathesis}

An individual's genetic makeup can confer significant risk in the development of both SUD and GD. The proportion of variability due to genetic factors ranges from 0.39 for hallucinogens to 0.72 for cocaine. ${ }^{33}$ GD's heritability is within this range at $0.50-0.60$ and is similar to heritability rates for alcohol and opiates. ${ }^{34}$ Recent theoretical work ${ }^{35}$ on the progression from initiation to addiction suggests that genetic contributions play a larger role in the later stages of the addiction process (eg, loss of control), whereas environmental experiences appear to mediate initial exposure and experimentation. ${ }^{36,37}$ These environmental contributions to the variability in risk for developing GD are reported to account for $38 \%-65 \%$ of the variance in problematic gambling behavior $^{38}$ and represent a significant factor in understanding the development of this disorder. Specific environmental factors identified as risk factors for GD include childhood maltreatment, ${ }^{39}$ parental gambling behavior and monitoring, ${ }^{40-42}$ cultural acceptance of gambling, ${ }^{40}$ and situational factors such as convenience of gambling establishments and prize characteristics. ${ }^{43}$

Much of the heritable risk for drug addiction is nonspecific and shared across substances. This shared risk is likely due to broad constructs such as impulsivity and negative affect, which have genetic underpinnings and may serve as risk factors for substance use. ${ }^{44}$ Not only do the risks associated with impulsivity and negative affect cut across substances of abuse, but a burgeoning literature also suggests that these constructs are risk factors for the development of several other externalizing disorders, including GD. ${ }^{34,45}$ For example, a prospective developmental study ${ }^{24}$ suggested that 1) underlying adolescent impulsivity influences the later development of both problematic gambling and depressogenic features, and that 2) these two sets of symptoms then bidirectionally perpetuate each other across late adolescence and early adulthood. Moreover, with respect to mechanistic investigations, the presence of the Taq A1 allele of the dopamine receptor D2 polymorphism has been linked to both GD and AUD. ${ }^{46}$ This allele has been associated with increases in impulsivity on neurocognitive tasks, ${ }^{47}$ suggesting the possibility that at least 
part of the shared genetic variance between GD and alcohol dependence $(12 \%-20 \%)^{48}$ is due to a genetic predisposition toward the underlying construct of impulsivity.

Taken together, these findings lend support for the syndrome model of addiction, which posits that different objects of addiction share core diatheses and sequelae. ${ }^{37}$ Although the end results are variable (eg, uncontrolled gambling versus uncontrolled heroin use), the underlying etiological substrates are highly overlapping, reflecting the phenomenon of multifinality, in which individuals with similar backgrounds in terms of risk and protective factors experience different developmental outcomes. ${ }^{49}$

\section{Neurobiology}

The pathway from genes to behavior is hierarchical, reciprocal, and is modulated at an intermediate level by neural circuitry, which is constructed largely by way of genetic activity and which functions to regulate phenotypic behavior. For example, the mesocorticolimbic dopamine pathway modulates the reward value of addictive substances and behaviors. ${ }^{35}$ A number of studies of GD and DUD have delineated genetic contributions to various aspects of this pathway, including density of D2 receptors and magnitude of dopamine release, which predict the subjective hedonic response. ${ }^{50}$

Just as genetic contributions to behavior are multifaceted, the phenomenon of addiction is far too complex to be mediated by a single neurocircuit. Additional networks involved in the addiction process include the nigrostriatal pathway, ${ }^{51}$ the hypothalamic-pituitary-adrenal (HPA) axis, ${ }^{52}$ the insula, ${ }^{53}$ and multiple prefrontal cortex (PFC) regions. ${ }^{54}$ As a broad neurobiological model of addiction, Koob and Le Moal ${ }^{36}$ postulated the existence of both 1) within-systems neuroadaptations, characterized by an elevated reward threshold (ie, tolerance) which are mediated by reductions in ventral striatum dopamine activity, as well as 2) between-systems neuroadaptations, in which anti-reward stress systems (eg, HPA axis, extended amygdala) are increasingly activated, causing a negative affect state (ie, withdrawal, craving) in the absence of the substance/behavior. These neuroadaptive changes are consistent with multistep theories of the progression to addiction ${ }^{35}$ and can be superimposed upon an impulsivity-to-compulsivity spectrum shift in which initial engagement in the addictive behavior results from an impulse-driven desire for the hedonic effects. Subsequent behavior follows the development of tolerance and allostatic changes in key neurocircuitry, and, in contrast to initial engagement, is driven by a habitual, compulsive desire to attenuate anxiety and negative affect (ie, reduce craving, avoid withdrawal). Evidence suggests that chronic substance use damages PFC networks critical for top-down modulation of behavior, reducing the ability to exercise the inhibitory control necessary for maintaining abstinence. ${ }^{55}$ This residual damage may also help explain why other addictive behaviors can develop after the cessation of an initial addictive behavior and why relapse after a period of abstinence is more likely when GD is comorbid with DUD.

Koob and Le Moal's ${ }^{36}$ model converges with support for predominant ventral striatal involvement in early drug use, followed by increasing dorsal striatum modulation as conditioned cues begin to supplant hedonic reward as the key motivator of behavior. ${ }^{56}$ In this context, individuals experience cravings following repeated pairings of sensory cues (eg, the "pssht" of a beer can) and addictive behaviors (eg, alcohol consumption), via the process of classical conditioning. Eventually, the attenuation of aversive states (eg, cravings, withdrawal) associated with the addictive behavior becomes the primary driving force for continued engagement in the behavior. Interestingly, damage to a subregion of the insula, which is responsible for assessing internal mood and sensory states, eliminates the experience of craving. ${ }^{57}$

In addition to the insula, another key neurobiological modulator of the anti-reward system is the HPA axis. This neuroendocrine pathway is disrupted with chronic exposure to substances, as well as during engagement in gambling, ${ }^{58}$ which alters its ability to function effectively and efficiently. ${ }^{52}$ The changes to the HPA axis resulting from repeated substance use include increases in circulating adrenocorticotropic hormone and corticosterone. These changes cause individuals with addictions to experience stress more intensely and for longer periods than others ${ }^{36}$ and lead to a long-term increase in their susceptibility to the negative effects of stress. ${ }^{59}$ Moreover, such modifications to the HPA axis are considered between-systems adaptations in the context of an addiction process, inasmuch as the recruitment of this stress response system partially mediates the experience of craving and predicts relapse. ${ }^{59}$

Although Koob and Le Moal's ${ }^{36}$ model was structured around substances, emerging evidence links key constructs involved in drug dependency to GD as well. For example, the impulsive-compulsive spectrum shift that occurs in DUD also takes place in GD. ${ }^{60}$ Additionally, on a molecular level, evidence indicates that dopamine D2 receptors underlie the experience of reward secondary to both gambling ${ }^{61}$ and substance use. ${ }^{62}$ With respect to the dopaminergic influence on GD, dopamine agonists, often utilized as pharmacotherapy for individuals with Parkinson's disease and restless leg 
syndrome, can lead to engagement in hedonic behaviors such as hypersexuality and gambling, ostensibly through dysregulation of the dopamine reward pathway. ${ }^{63}$ Conversely, pharmacotherapy with dopamine antagonists has shown some efficacy in treating alcohol dependence, ${ }^{64}$ although evidence has yet to support the efficacy of this approach in GD. ${ }^{65,66}$ Finally, as in DUD, the inability of individuals with GD to exhibit appropriate top-down impulse control may result from combinations of increases in sympathetic nervous system activity during gambling, ${ }^{67}$ coupled with hyperactive stress systems,${ }^{58}$ as well as decreased activation in crucial PFC networks. ${ }^{68}$

In spite of significant progress in elucidating the neurobiological underpinnings of both GD and DUD, much work remains to be done. Although strides have been made in integrating GD into preexisting models of DUD, the GD literature is still lacking in a complete and thorough understanding of the role of dopamine in the development of the disorder, which prevents its full inclusion in these broad theoretical models of addiction. ${ }^{35-36}$ Moreover, it is clear that neurotransmitters aside from dopamine contribute significantly to the addiction process, ${ }^{54}$ but the empirical evidence involving serotonin, norepinephrine, and glutamate in GD is sparse. ${ }^{69}$

\section{Neurocognition}

Addictive disorders are commonly associated with cognitive deficits, although there is significant variability in observed outcomes based upon the specific substance abused, as well as the intensity and chronicity of use. In individuals with alcoholism, deficits occur in the domains of executive functions (EFs) and visuospatial skills, while other abilities such as language and gross motor abilities are relatively spared. ${ }^{70}$ Fortunately, these impairments resulting from chronic use can be at least partially ameliorated with prolonged abstinence. Individuals with GD also exhibit deficits in EFs, ${ }^{71}$ including decision making, ${ }^{72}$ inhibitory control, ${ }^{73}$ and mental flexibility ${ }^{74}$ however, no studies to date have examined the impact of prolonged abstinence from gambling on these deficits. Another unresolved question in this literature pertains to whether these neurocognitive deficits are present premorbidly or whether they represent downstream phenotypic effects of physiological changes due to addictive behaviors. Several studies in GD and alcohol dependence generally support the presence of premorbid impulsivity in the larger population of individuals with addictions, although data from these investigations also indicate greater impairment in EFs such as working memory among individuals with alcohol dependence compared to those with GD, ${ }^{75}$ possibly suggesting that chronic ethanol ingestion selectively damages PFC circuitry. Moreover, convergent with neurocognitive findings, self-report data show that trait impulsivity tends to be elevated in GD, providing independent, multimodal evidence for preexisting inhibitory control deficits in addictive disorders. ${ }^{73,76}$

Overall, findings regarding neurocognitive deficits in GD are informative, especially with respect to investigations in which GD is utilized as a behavioral model of addiction in order to address specific research questions. ${ }^{75}$ However, a key limitation that has persisted in this literature is heterogeneity in cognitive tasks employed across studies, which limit direct comparisons and aggregate analyses. ${ }^{77}$ Importantly, this line of research is still in its infancy, and as it continues to develop, more precise comparisons of neurocognitive profiles can be made between individuals with GD and those who abuse substances such as alcohol. Replicating findings across similar tasks and engaging in more prospective longitudinal designs ${ }^{74}$ will solidify our understanding of impulsivity and other important cognitive constructs as they relate to both GD and DUD.

\section{Treatment}

Approximately, a third of individuals with GD and about one-quarter of those with alcohol dependence will recover naturally without need for treatment. ${ }^{78,79}$ Others will turn to treatment options including self-help and peer support, brief and motivational interventions, and cognitive-behavioral therapy (CBT) in order to regain control of their addictive behavior. These gambling treatments are largely based on those developed for alcohol and drug addictions, and research suggests that gamblers, ${ }^{80}$ like those with substance-related addictions, ${ }^{81}$ benefit from such interventions. However, gambling treatment is not as widely available. In the following section, we briefly discuss common interventions for substance and gambling problems.

\section{2-Step recovery program}

Alcoholics Anonymous (AA) is a peer-led support group for those with alcohol use problems. AA meetings are widely available in the US and research indicates that participation is common and associated with improved outcomes. Kelly et $\mathrm{al}^{82}$ followed alcohol-dependent patients who were encouraged to engage in support groups following discharge from intensive outpatient treatment and 79\% accessed these groups in the first year. Participation declined but remained substantial in the second (54\%) and third (54\%) years postdischarge and was associated with better drinking outcomes. 
Other studies ${ }^{83,84}$ suggest that benefits of AA participation may be optimal when patients engage in AA in concert with professional treatment and that AA participation may be an important component in long-term recovery.

Gamblers anonymous (GA) is based on the 12-step philosophy pioneered by AA, and it espouses many of the principles found in AA, including an abstinence-only orientation, adoption of the disease model of addiction, and conceptualization of addiction as a chronic illness. GA appears to benefit those with greater addiction severity, ${ }^{85}$ but the aforementioned characteristics (eg, abstinence orientation) may reduce its appeal for some individuals. There is relatively little data on GA as a stand-alone treatment, but available studies ${ }^{85-87}$ suggest that GA's benefits as a sole intervention are modest, possibly as a consequence of high drop-out rates. However, GA involvement in concert with professional treatment does seem to enhance treatment outcomes, ${ }^{88}$ and it remains a recommended component of some professionally delivered treatments. ${ }^{89}$

\section{Self-help}

Self-help treatments offer many benefits not found in 12-step meetings or professionally delivered approaches such as privacy, cost savings, convenience, and accessibility. ${ }^{90}$ Bibliotherapy for alcohol problems generates small to medium effect sizes compared to no treatment controls, may be equally effective as more extensive interventions, and appears to lead to maintenance of treatment gains over long periods. ${ }^{91}$ Bibliotherapy has also been evaluated for problem gambling and is beneficial for gamblers relative to those randomized to wait-list controls..$^{92}$ However, a randomized controlled trial (RCT) $)^{93}$ and its 24-month follow-up ${ }^{94}$ suggest that limited therapist contact may be an important component of effective bibliotherapy for gambling problems.

\section{Motivational interventions}

Motivational interventions may be ideal options for those with addictions who are ambivalent about changing behavior or seeking treatment. Meta-analysis of 55 randomized or quasi-randomized studies concluded that motivational interventions for those with AUD/DUD lead to significant reductions in drinking and substance use outcomes relative to no treatment controls and comparable outcomes relative to other active treatments. ${ }^{95}$ Similarly, motivational approaches are an efficacious intervention for gambling problems. An RCT demonstrated that single-session motivational interventions of $\sim 75$ minutes can be effective among problem gamblers in reducing gambling frequency and dollars wagered compared to a control interview, with effects persisting up to a year following the intervention. ${ }^{96}$ More time-limited formats (eg, 10-15 minutes), including brief advice and personalized feedback, show promise for changing some gambling behaviors in those with problem or disordered level gambling. ${ }^{97,98}$ Interestingly, more extensive formats (eg, four sessions) of motivational enhancement combined with CBT do not consistently improve outcomes relative to brief or single-session formats in RCTs of individuals with problem or disordered gambling recruited from community ${ }^{98}$ and college student ${ }^{99}$ populations. This effect may be due to the inclusion of subclinical gamblers in these studies, who may not need or desire extensive treatments. For others, particularly those with GD, professionally delivered treatments of longer duration may be necessary for behavior change.

\section{Cognitive and/or behavioral therapies}

Professionally delivered, manual-guided CBT improves outcomes relative to GA or self-directed bibliotherapy in those with GD in RCTs. ${ }^{86,88}$ However, in an RCT ${ }^{100}$ that included less severe college student gamblers, a 4- to 6-session CBT condition did not yield improved outcomes relative to a single session of personalized feedback. Other studies examining format (group versus individual) or comparisons of CBT to other active therapies generally find no differences amongst the comparisons groups. ${ }^{101-103}$ These findings mirror evidence from the treatment of alcohol dependence. ${ }^{104}$

Although CBT for gambling is very similar to CBT for substance abuse treatment, cognitive therapies that focus explicitly on the distorted cognitions related to gambling are more unique in content. These therapies often involve more therapist contact (eg, up to 20 sessions) and demonstrate robust benefits relative to wait-list controls. ${ }^{105,106}$ However, these results will need to be replicated using larger sample sizes and using intent-to-treat analyses, as these studies ${ }^{105,106}$ excluded individuals who dropped out of treatment resulting in inflated treatment effects. Similar to other studies finding few differences among gambling treatments, ${ }^{101}$ an $\mathrm{RCT}^{107}$ that compared cognitive therapy to other active therapies (eg, motivational interviewing, behavioral therapy) and used intent-to-treat analyses found no significant differences in gambling outcomes among the therapies.

Overall, AUD/DUD and gambling treatment research to date suggests that no one format or approach is ideal. Rather, it appears that most treatments are beneficial, with few differences found between active treatments when pitted against one another. Thus, persons with addictions who desire treatment have a wide range of options available to 
them based on preferences, needs, and perhaps severity of their disorder. Moving forward, therapies may need to increasingly incorporate content that addresses the high comorbidity between GD and other psychiatric disorders, including, anxiety, mood, personality, alcohol, and drug disorders. ${ }^{22}$ Evidence suggests that psychiatric symptoms are responsive to and improve during gambling treatment. ${ }^{108}$ However, room for further improvement in psychiatric symptoms remains among those with more severe presentations, ${ }^{109}$ suggesting that these individuals need specialized and integrated content to address comorbid conditions.

\section{Conclusion}

A major challenge in comprehensively delineating links and risks across GD and AUD/DUD pertains to the asymmetrical nature of research on addiction-related disorders in which GD is a nascent field of inquiry with a dearth of funding in comparison to other addictions. ${ }^{110}$ Nevertheless, recent investigations have begun to elucidate the developmental progression of GD, ${ }^{111}$ suggesting that the etiology of GD is complex, epigenetic, and includes a multitude of both proximal and distal predictors. Moreover, these models are similar in nature to developmental psychopathology models of AUD/DUD, suggesting significant overlap and common risk factors. As evidence accumulates, we are able to integrate decades of research into broad, inclusive models of addiction $^{37}$ that incorporate behavioral addictions such as GD.

Research addressing questions such as harms and economic costs related to subclinical gambling and whether subclinical gamblers experience negative consequences on par with the milder diagnostic forms of AUD/DUD is needed. These studies will be important for future DSM revisions regarding decisions about whether to model GD criteria and thresholds more closely to those for AUD/DUD. Another research priority is investigation of treatment approaches, particularly integrated treatments that address comorbid disorders or underlying dysfunctions (eg, impulsivity). The high rates of comorbidity suggest that such integrated treatments are an area of high need and have great potential. Unfortunately, the GD treatment literature is less well developed in this respect than other addictions.

In terms of clinical practice, we recommend screening for non-gambling psychiatric disorders among those seeking treatment for gambling problems. Routine screening for psychiatric disorders among treatment-seeking gamblers may help these patients obtain needed treatment for comorbid disorders more quickly and has the potential to improve response to both GD and the comorbid disorder when such treatment is offered concurrently or in an integrated manner. In addition, within AUD/DUD treatment clinics, the higher prevalence of gambling disorder within this population suggests that systematic screening for gambling problems is warranted. ${ }^{31,112}$

GD, as the first nonsubstance behavioral addiction, sets the bar for consideration of other disorders as behavioral addictions in the future. As reviewed, GD shares many features across many domains with AUD/DUD, leading some investigators $^{37}$ to espouse a syndrome model of addiction, which highlights the etiological overlap across the various manifestations of addiction (eg, uncontrolled gambling, alcohol use, or cocaine use). Researchers and clinicians alike should account for the substantial overlap in these conditions when conceptualizing psychopathology for the varied purposes of designing research studies, assessing for clinical symptomatology, and planning treatment.

\section{Acknowledgments}

Preparation of this report was supported in part by $\mathrm{NIH}$ grants: P60-AA003510, R01-AA021446, R21-DA031897, R01-DA-033411-01A1, and a National Center for Responsible Gaming grant.

\section{Disclosure}

The authors report no conflicts of interest in this work.

\section{References}

1. American Psychiatric Association. Diagnostic and Statistical Manual of Mental Disorders. 5th ed. Washington, DC: American Psychiatric Association, 2013.

2. Lesieur HR, Rosenthal RJ. Pathological gambling: a review of the literature (prepared for the American Psychiatric Association Task Force on DSM-IV Committee on disorders of impulse control not elsewhere classified). J Gambl Stud. 1991;7(1):5-39.

3. Schuckit MA. Editor's corner: DSM-5 - ready or not, here it comes. J Stud Alcohol Drugs. 2013;74(5):661-663.

4. Weinstock J, Burton S, Rash CJ, et al. Predictors of engaging in problem gambling treatment: data from the West Virginia Gamblers Help Network. Psychol Addict Behav. 2011;25(2):372-379.

5. Weinstock J, Scott TL, Burton S, et al. Current suicide ideation in gamblers calling a helpline. Addict Res Theory. 2014;22(5):398-406.

6. Bischof A, Meyer C, Bischof G, Kastirke N, John U, Rumpf H. Comorbid Axis I-disorders among subjects with pathological, problem, or at-risk gambling recruited from the general population in Germany: results of the PAGE study. Psychiatry Res. 2013;210(3):1065-1070.

7. Moghaddam JF, Yoon G, Dickerson DL, Kim SW, Westemeyer J. Suicidal ideation and suicide attempts in five groups with different severities of gambling: findings from the National Epidemiologic Survey on Alcohol and Related Conditions. Am J Addict. 2015;24:292-298.

8. Weinstock J, Rash CJ, Burton S, et al. Examination of proposed DSM-5 changes to pathological gambling in a helpline sample. J Clin Psychol. 2013;69(12):1305-1314.

9. Morasco B, Weinstock J, Ledgerwood LM, Petry NM. Psychological factors that promote and inhibit pathological gambling. Cogn Behav Prac. 2007;14:206-217. 
10. Tavares H, Zilberman ML, Hodgins DC, el-Guebaly N. Comparison of craving between pathological gamblers and alcoholics. Alcohol Clin Exp Res. 2005;29(8):1427-1431.

11. Ashrafioun L, Kostek J, Ziegelmeyer E. Assessing post-cue exposure craving and its association with amount wagered in an optional betting task. J Behav Addict. 2013; 2(3):133-137.

12. Young MM, Wohl MJA. The Gambling Craving Scale: psychometric validation and behavioral outcomes. Psychol Addict Behav. 2009;23(3):512-522.

13. Hasin DS, Grant BF. The National Epidemiologic Survey on Alcohol and Related Conditions (NESARC) Waves 1 and 2: review and summary of findings. Soc Psychiatry Psychiatr Epidemiol. Epub 2015 July 26.

14. Gerstein D, Volberg RA, Toce MT, et al. Gambling Impact and Behavior Study: Report to the National Gambling Impact Study Commission. Chicago, IL: National Opinion Research Center, 1999.

15. Kessler RC, Hwang I, LaBrie R, et al. The prevalence and correlates of DSM-IV pathological gambling in the National Comorbidity Survey Replication. Psychol Med. 2008;38(9):1351-1360.

16. Petry NM, Stinson FS, Grant BF. Comorbidity of DSM-IV pathological gambling and other psychiatric disorders: results from the National Epidemiological Survey on Alcohol and Related Conditions. J Clin Psychiatry. 2005;66:564-574.

17. Welte J, Barnes G, Wieczorek W, Tidwell M-C. Alcohol and gambling pathology among US adults: prevalence, demographic patterns and comorbidity. J Studies Alcohol. 2001;62:706-712.

18. Petry NM, Blanco C, Auriacombe M, et al. An overview of and rationale for changes proposed for pathological gambling in DSM-5. J Gambl Stud. 2014;30:493-502.

19. Petry NM, Blanco C, Stinchfield R, Volberg R. An empirical evaluation of proposed changes for gambling diagnosis in the DSM-5. Addiction. 2012;108:575-581.

20. Weinstock J, Rash CJ. Clinical and research implications of gambling disorder in DSM-5. Curr Addict Rep. 2014;1:159-165.

21. Brewer JA, Potenza MN, Desai RA. Differential association between problem and pathological gambling and psychiatric disorders in individuals with or without alcohol abuse or dependence. CNS Spectrum. 2010;1:33-44.

22. Chou KL, Afifi TO. Disordered (pathological or problem) gambling and axis I psychiatric disorders: results from the National Epidemiological Survey on Alcohol and Related Conditions. Am J Epidemiol. 2011;173(11):1289-1297.

23. Parhami I, Mojtabai RM, Rosenthal RJ, Afifi TO, Fong TW. Gambling and the onset of comorbid mental disorders: a longitudinal study evaluating severity. J Psychiatr Pract. 2014;20:207-219.

24. Dussault F, Brendgen M, Vitaro F, Wanner B, Tremblay RE. Longitudinal links between impulsivity, gambling problems and depressive symptoms: a transactional model from adolescence to early adulthood. J Child Psychol Psychiatr. 2011;52:130-138.

25. Lorains FK, Cowlishaw S, Thomas SA. Prevalence of comorbid disorders in problem and pathological gambling: systematic review and meta-analysis of population studies. Addiction. 2011;106:490-498.

26. Abdollahnejad R, Delfabbro P, Denson L. Psychiatric comorbidity in problem and pathological gamblers: investigating the confounding influence of alcohol use disorders. Addict Behav. 2014;39: 566-572.

27. Dowling NA, Colishaw S, Jackson AC, Merkouris SS, Francis KL, Christensen DR. Prevalence of psychiatric co-morbidity in treatmentseeking problem gamblers: a systematic review and meta-analysis. Aust NZ J Psychiatry. 2015;49(6):519-539.

28. Hodgins DC, el-Guebaly N. The influence of substance dependence and mood disorders on outcome from pathological gambling: five-year follow-up. J Gambl Stud. 2010;26(1):117-127.

29. Kausch O. Patterns of substance abuse among treatment-seeking pathological gamblers. J Subst Abuse Treat. 2003;25:263-270.

30. Rash CJ, Weinstock J, Petry NM. Drinking patterns of pathological gamblers before, during, and after gambling treatment. Psychol Addict Behav. 2011;25(4):664-674.
31. Cowlishaw S, Merkouris S, Chapman A, Radermacher H. Pathological and problem gambling in substance use treatment: a systematic review and meta-analysis. J Subst Abuse Treat. 2014;46:98-105.

32. Ledgerwood DM, Downey KK. Relationship between problem gambling and substance use in a methadone maintenance population. Addict Behav. 2002;27(4):483-491.

33. Goldman D, Oroszi G, Ducci F. The genetics of addictions: uncovering the genes. Nat Rev Genet. 2005;6(7):521-532.

34. Lobo DS, Kennedy JL. Genetic aspects of pathological gambling: a complex disorder with shared genetic vulnerabilities. Addiction 2009;104(9):1454-1465.

35. Piazza PV, Deroche-Gamonet V. A multistep general theory of transition to addiction. Psychopharmacol. 2013;229(3):387-413.

36. Koob GF, Le Moal M. Addiction and the brain antireward system. Annu Rev Psychol. 2008;59:29-53.

37. Shaffer HJ, LaPlante DA, LaBrie RA, Kidman RC, Donato AN, Stanton MV. Toward a syndrome model of addiction: multiple expressions, common etiology. Harv Rev Psychiatry. 2004;12(6): 367-374.

38. Shah KR, Eisen SA, Xian H, Potenza MN. Genetic studies of pathological gambling: a review of methodology and analyses of data from the Vietnam era twin registry. J Gambl Stud. 2005;21(2):179-203.

39. Hodgins DC, Schopflocher DP, el-Guebaly N, et al. The association between childhood maltreatment and gambling problems in a community sample of adult men and women. Psychol Addict Behav. 2010;24(3):548.

40. Raylu N, Oei TPS. Pathological Gambling: a comprehensive review. Clin Psychol Rev. 2002;22(7):1009-1061.

41. Schreiber L, Odlaug BL, Kim SW, Grant JE. Characteristics of pathological gamblers with a problem gambling parent. Am J Addict. 2009;18(6):462-469.

42. Lee GP, Stuart EA, Ialongo NS, Martins SS. Parental monitoring trajectories and gambling among a longitudinal cohort of urban youth. Addiction. 2014;109(6):977-985.

43. Wood RTA, Griffiths MD, Parke J. Impact of tasks and users' characteristics on virtual reality performance. CyberPsychol Behav. 2007;10(3):354-361.

44. Verdejo-García A, Lawrence AJ, Clark L. Impulsivity as a vulnerability marker for substance-use disorders: review of findings from high-risk research, problem gamblers and genetic association studies. Neurosci Biobehav. 2008;32(4):777-810.

45. Slutske WS, Eisen S, Xian H, et al. A twin study of the association between pathological gambling and antisocial personality disorder. J Abnorm Psychol. 2001;110(2):297-308

46. Comings DE, Gade Andavolu R, Gonzalez N, et al. The additive effect of neurotransmitter genes in pathological gambling. Clin Genet. 2001;60(2):107-116.

47. Rodriguez-Jimenez R, Avila C, Ponce G, et al. The TaqIA polymorphism linked to the DRD2 gene is related to lower attention and less inhibitory control in alcoholic patients. Eur Psychiatry. 2006;21(1):66-69.

48. Slutske WS, Eisen S, True WR, Lyons MJ, Goldberg J, Tsuang M. Common genetic vulnerability for pathological gambling and alcohol dependence in men. Arch Gen Psychiatry. 2000;57(7):666-673.

49. Beauchaine TP, Neuhaus E, Brenner SL, Gatzke-Kopp L. Ten good reasons to consider biological processes in prevention and intervention research. Dev Psychopathol. 2008;20(3):745-774.

50. Jentsch JD, Pennington ZT. Reward, interrupted: inhibitory control and its relevance to addictions. Neuropharmacol. 2014;76(Part B): 479-486.

51. Wise RA. Roles for nigrostriatal-not just mesocorticolimbicdopamine in reward and addiction. Trends Neurosci. 2009;32(10): $517-524$.

52. Zhou Y, Proudnikov D, Yuferov V, Kreek MJ. Drug-induced and genetic alterations in stress-responsive systems: implications for specific addictive diseases. Brain Res. 2010;1314:235-252.

53. Naqvi NH, Bechara A. The hidden island of addiction: the insula. Trends Neurosci. 2009;32(1):56-67. 
54. Volkow ND, Baler RD. Addiction science: uncovering neurobiological complexity. Neuropharmacol. 2014;76:235-249.

55. Volkow ND, Wang GJ, Fowler JS, Tomasi D, Telang F. Addiction: beyond dopamine reward circuitry. Proc Natl Acad Sci. 2011;108(37): 15037-15042.

56. Volkow ND, Wang GJ, Telang F, et al. Cocaine cues and dopamine in dorsal striatum: mechanism of craving in cocaine addiction. J Neurosci. 2006;26(24):6583-6588.

57. Naqvi NH, Rudrauf D, Damasio H, Bechara A. Damage to the insula disrupts addiction to cigarette smoking. Science. 2007;315(5811): 531-334.

58. Meyer G, Schwertfeger J, Exton MS, et al. Neuroendocrine response to casino gambling in problem gamblers. Psychoneuroendocrinology. 2004;29(10):1272-1280.

59. Sinha R. How does stress lead to risk of alcohol relapse? Alcohol Res. 2012;34(4):432-440.

60. Brewer JA, Potenza MN (2008). The neurobiology and genetics of impulse control disorders: relationships to drug addictions. Biochem Pharmacol. 2008;75(1):63-75.

61. Zack M, Poulos CX. A D2 antagonist enhances the rewarding and priming effects of a gambling episode in pathological gamblers. Neuropsychopharmacology. 2007;32(8):1678-1686.

62. Volkow ND, Wang GJ, Fowler JS, et al. Reinforcing effects of psychostimulants in humans are associated with increases in brain dopamine and occupancy of D2 receptors. J Pharmacol Exp Ther. 1999;291(1):409-415.

63. Driver-Dunckley ED, Noble BN, Hentz JG, et al. Gambling and increased sexual desire with dopaminergic medications in restless legs syndrome. Clin Neuropharmacol. 2007;30(5):249-255.

64. Hutchison KE, Ray L, Sandman E, et al. The effect of olanzapine on craving and alcohol consumption. Neuropsychopharmacology. 2006;31(6):1310-1317.

65. Fong T, Kalechstein A, Bernhard B, Rosenthal R, Rugle L. A doubleblind, placebo-controlled trial of olanzapine for the treatment of video poker pathological gamblers. Pharmacol Biochem Behav. 2008;89(3):298-303.

66. McElroy SL, Nelson EB, Welge JA, Kaehler L, Keck PE. Olanzapine in the treatment of pathological gambling: a negative randomized placebocontrolled trial. J Clin Psychiatry. 2008;69(3):433-440.

67. Krueger TH, Schedlowski M, Meyer G. Cortisol and heart rate measures during casino gambling in relation to impulsivity. Neuropsychobiology. 2005;52(4):206-211.

68. Potenza MN, Leung HC, Blumberg HP, et al. An FMRI Stroop task study of ventromedial prefrontal cortical function in pathological gamblers. Am J Psychiatry. 2003;160(11):1990-1994.

69. Leeman RF, Potenza MN. Similarities and differences between pathological gambling and substance use disorders: a focus on impulsivity and compulsivity. Psychopharmacol. 2012;219(2):469-490.

70. Stavro K, Pelletier J, Potvin S. Widespread and sustained cognitive deficits in alcoholism: a meta-analysis. Addict Biol. 2013;18(2):203-213.

71. Ledgerwood DM, Alessi SM, Phoenix N, Petry NM. Behavioral assessment of impulsivity in pathological gamblers with and without substance use disorder histories versus healthy controls. Drug Alcohol Depend. 2009;105(1):89-96.

72. Brand M, Kalbe E, Labudda K, Fujiwara E, Kessler J, Markowitsch HJ. Decision-making impairments in patients with pathological gambling. Psychiatry Res. 2005;133(1):91-99.

73. Fuentes D, Tavares H, Artes R, Gorenstein C. Self-reported and neuropsychological measures of impulsivity in pathological gambling. J IntNeuropsychol Soc. 2006;12(06):907-912.

74. Vitaro F, Arseneault L, Tremblay RE. Impulsivity predicts problem gambling in low SES adolescent males. Addiction. 1999;94(4): $565-575$.

75. Lawrence AJ, Luty J, Bogdan NA, Sahakian BJ, Clark L. Problem gamblers share deficits in impulsive decision-making with alcoholdependent individuals. Addiction. 2009;104(6):1006-1015.
76. Slutske WS, Caspi A, Moffitt TE, Poulton R. Personality and problem gambling: a prospective study of a birth cohort of young adults. Arch Gen Psychiatry. 2005;62(7):769-775.

77. Goudriaan AE, Oosterlaan J, de Beurs E, Van den Brink W. Pathological gambling: a comprehensive review of biobehavioral findings. Neurosci Biobehav Rev. 2004;28(2):123-141.

78. Dawson DA, Grant BF, Stinson FS, Chou PS, Huang B, Ruan WJ. Recovery from DSM-IV alcohol dependence: United States, 2001-2002. Addiction. 2005;100(3):281-292.

79. Slutske WS. Natural recovery and treatment-seeking in pathological gambling: results of two U.S. national surveys. Am J Psychiatry. 2006;163(2):297-302.

80. Rash CJ, Petry NM. Psychological treatments for gambling disorder. Psychol Res Behav Manag. 2014;7:285-295.

81. Dutra L, Stathopoulou G, Basden SL, Leyro TM, Powers MB, Otto MW. A meta-analytic review of psychosocial interventions for substance use disorders. Am J Psychiatry. 2008;165(2):179-187.

82. Kelly JF, Stout RL, Zywiak W, Schneider R. A 3-year study of addiction mutual help group participation following intensive outpatient treatment. Alcohol Clin Exp Res. 2006;30(8):1381-1392.

83. Moos RH, Moos BS. Participation in treatment and Alcoholics Anonymous: a 16-year follow-up of initially untreated individuals. J Clin Psychol. 2006;62(6):735-750.

84. Moos RH, Moos BS. Paths of entry into alcoholics anonymous: consequences for participation and remission. Alcohol Clin Exp Res. 2005;29(10):1858-1868.

85. Petry NM. Patterns and correlates of Gamblers Anonymous attendance in pathological gamblers seeking professional treatment. Addict Behav. 2003;28(6):1049-1062.

86. Grant JE, Donahue CB, Odlaug BL, Kim SW, Miller MJ, Petry NM. Imaginal desensitization plus motivational interviewing for pathological gambling: randomised controlled trial. $\mathrm{Br} J$ Psychiatry. 2009;195(3):266-267.

87. Stewart RM, Brown RI. An outcome study of Gamblers Anonymous. Br J Psychiatry. 1988;152(2):284-288.

88. Petry NM, Ammerman Y, Bohl J, et al. Cognitive-behavioral therapy for pathological gamblers. J Consult Clin Psychol. 2006;74(3):555-556.

89. Petry NM. Pathological Gambling: Etiology, Ccomorbidity, and Treatment. Washington, DC: American Psychological Association; 2005.

90. Gainsbury S, Blaszczynski A. Online self-guided interventions for the treatment of problem gambling. Int Gambl Stud. 2011;11:289-308.

91. Apodaca TR, Miller WR. A meta-analysis of the effectiveness of bibliotherapy for alcohol problems. J Clin Psychol. 2003;59(3): 289-304.

92. LaBrie RA, Peller AJ, LaPlante DA, et al. A brief self-help toolkit intervention for gambling problems: a randomized multisite trial. $\mathrm{Am}$ J Orthopsychiatry. 2012;82(2):278-289.

93. Hodgins DC, Currie SR, el-Guebaly N. Motivational enhancement and self-help treatments for problem gambling. J Consult Clin Psychol. 2001;69(1):50-57.

94. Hodgins DC, Currie S, el-Guebaly N, Peden N. Brief motivational treatments for problem gambling: a 24-month follow-up. Pyschol Addict Behav. 2004;18(3):293-296.

95. Smedslund G, Berg RC, Hammerstrøm KT, et al. Motivational interviewing for substance abuse. Cochrane Database Syst Rev. 2011;(5):CD008063.

96. Diskin KM, Hodgins DC. A randomized controlled trial of a single session motivational intervention for concerned gamblers. Behav Res Ther. 2009;47(5):382-388.

97. Cunningham JA, Hodgins DC, Toneatto T, Rai A, Cordingley J. Pilot study of a personalized feedback intervention for problem gamblers. Behav Ther. 2009;40(3):219-224.

98. Petry NM, Weinstock J, Ledgerwood DM, Morasco B. A randomized trial of brief interventions for problem and pathological gamblers. J Consult Clin Pscyhol. 2008;76(2):318-328. 
99. Petry NM, Weinstock J, Morasco BJ, Ledgerwood DM. Brief motivational interventions for college student problem gamblers. Addiction. 2009;104(9):1569-1578.

100. Larimer ME, Neighbors C, Lostutter TW, et al. Brief motivational feedback and cognitive behavioral interventions for prevention of disordered gambling: a randomized clinical trial. Addiction. 2011;107(6):1148-1158.

101. Carlbring P, Jonsson J, Josephson H, Forsberg L. Motivational interviewing versus cognitive behavioral group therapy in the treatment of problem and pathological gambling: a randomized controlled trial. Cogn Behav Ther. 2010;39(2):92-103.

102. Dowling N, Smith D, Thomas T. A comparison of individual and group cognitive-behavioural treatment for female pathological gambling. Behav Res Ther. 2007;45(9):2192-2202.

103. Jimenez-Murcia S, Aymami N, Gomez-Peña M, et al. Does exposure and response prevention improve the results of group cognitivebehavioural therapy for male slot machine pathological gamblers? Br J Clin Psychol. 2012;51(1):54-71.

104. Project Match Research Group. Matching alcoholism treatments to client heterogeneity: Project MATCH posttreatment drinking outcomes. J Stud Alcohol. 1997;58:7-29.

105. Ladouceur R, Sylvain C, Boutin C, et al. Cognitive treatment of pathological gambling. J Nerv Ment Dis. 2001;189(11):774-780.
106. Ladouceur R, Sylvain C, Boutin C, Lachance S, Douet C, Leblond J. Group therapy for pathological gamblers: a cognitive approach. Behav Res Ther. 2003;41(5):587-596.

107. Toneatto T, Gunaratne M. Does the treatment of cognitive distortions improve clinical outcomes for problem gambling? J Contemp Psychother. 2009;39:221-229.

108. Jiminez-Murcia S, Granero R, Fernandez-Aranda F, et al. Predictors of outcome among pathological gamblers receiving cognitive behavioral group therapy. Euro Addict Res. 2015;21:169-178.

109. Moghaddam JF, Campos MD, Myo C, Reid RC, Fong TW. A longitudinal examination of depression among gambling inpatients. $J \mathrm{Gambl}$ Stud. 2015;31(4):1245-1255.

110. Petry NM, Blanco C. National gambling experiences in the United States: will history repeat itself? Addiction. 2012;108(6):1032-1037.

111. Blanco C, Hanania J, Petry NM, et al. Towards a comprehensive developmental model of pathological gambling. Addiction. 2015;110(8) 1340-1351.

112. Leavens E, Marotta J,Weinstock J. Disordered gambling in residential substance use treatment centers: an unmet need. J Addict Dis. 2014;33(2):163-173.

\section{Publish your work in this journal}

Substance Abuse and Rehabilitation is an international, peer-reviewed, open access journal publishing original research, case reports, editorials, reviews and commentaries on all areas of addiction and substance abuse and options for treatment and rehabilitation. The manuscript management system is completely online and includes a very quick and fair peer-review system. Visit http://www.dovepress.com/testimonials.php to read real quotes from published authors. 